\title{
LETTERS
}

\section{Reflections on sexism in medicine}

I wish to comment on the recent article on sexism in medical care by Manzoor and Redelmeier. ${ }^{1}$ I recognize that the authors wished to draw attention to the issue of sexism in medicine, but the article missed the mark in several ways and overlooked valuable opportunities to promote allyship and advocacy for women in medicine.

The piece involves a female medical trainee being mistaken for a nurse. This situation is hardly a rarity, and female physicians do not need to be told how to manage it. For most of us, an appropriate response is something along the lines of, "Actually I'm your doctor - Dr. X - but what can I do to help you"? Helping a patient with requests typically directed to nurses is not "beneath" any physician man or woman. In a way, such requests are complimentary, because nurses belong to an exceptionally caring and compassionate profession. Most patients who mistake physicians for nurses are apologetic once roles have been clarified.

The article's whimsical tone makes light of the real day-to-day struggles of women in medicine. These challenges are not easily overcome by a few pithy phrases crafted by a senior male colleague who, by virtue of being a man, has never had to contend with sexism or the toll it can exact. By way of disclosure, I am a colleague and former trainee of Dr. Redelmeier, the senior author of the article on sexism in medical care, and have shared with him my views as well as some of the concerns shared with me by others. I also provided him a draft of this letter for his feedback before submitting it. Likewise, as a straight white woman, I have little insight into the difficulties faced by colleagues of different racial backgrounds or orientations.

Also, the article says nothing of the damaging casual sexism female physicians continue to experience in the workplace, even in 2020. Better examples to have highlighted might include men "talking over" female colleagues in meetings, women being addressed by their first names while men are addressed as "Doctor," and the exclusion of women from leadership roles. The list goes on. In fact, the article itself has been interpreted by some as "mansplaining," unintentionally reinforcing the very phenomenon it was meant to address.

I appreciate that the authors invited presubmission feedback on their article from many women in medicine and accept that some may not share my view. It is clear, however, that many do. My concerns about the article have been reinforced by several female residents who approached me in my capacity as an internal medicine site program director with their own concerns. Women in medicine have had to confront sexism for as long as there have been women in medicine. Thoughtful solutions and allyship in dealing with micro- and macroaggressions would be both more helpful and more widely appreciated.

\section{Lynfa Stroud MD MEd}

Associate professor, Division of General Internal Medicine, University of Toronto; Site program director, Internal Medicine, and staff physician, Division of General Internal Medicine, Sunnybrook Health Sciences Centre, Toronto, Ont.

Cite as: CMAJ 2020 March 23;192:E324. doi: 10.1503/cmaj.74909

\section{Reference}

1. Manzoor F, Redelmeier DA. Sexism in medical care: "Nurse, can you get me another blanket?". CMAJ 2020;192:E119-20.

Competing interests: None declared. 